\title{
A Design Of Feeding Network For A Dual-Linear Polarization, Stacked, Probe-Fed Microstrip Patch Antenna Array
}

\author{
Jaworski, G.; Krozer, Viktor
}

Published in:

15th Intern. Conf. on Microwaves, Radar and Wireless Communications

Publication date:

2004

Document Version

Publisher's PDF, also known as Version of record

Link back to DTU Orbit

Citation (APA):

Jaworski, G., \& Krozer, V. (2004). A Design Of Feeding Network For A Dual-Linear Polarization, Stacked, ProbeFed Microstrip Patch Antenna Array. In 15th Intern. Conf. on Microwaves, Radar and Wireless Communications: Proc. 1st European Radar Conference (pp. 305-308). IEEE.

\section{General rights}

Copyright and moral rights for the publications made accessible in the public portal are retained by the authors and/or other copyright owners and it is a condition of accessing publications that users recognise and abide by the legal requirements associated with these rights.

- Users may download and print one copy of any publication from the public portal for the purpose of private study or research.

- You may not further distribute the material or use it for any profit-making activity or commercial gain

- You may freely distribute the URL identifying the publication in the public portal 


\title{
A DESIGN OF FEEDING NETWORK FOR A DUAL-LINEAR POLARIZATION, STACKED, PROBE-FED MICROSTRIP PATCH ANTENNA ARRAY
}

\author{
Grzegorz Jaworski, Viktor Krozer *
}

\begin{abstract}
Components of multilayer feed network are presented for application in broad-band duallinear polarized stacked C-band antenna. Measurement results of wide band matching circuits and different types of power divider networks constituting parts of BFN demonstrate wideband operation. Suitable matching of individual patches as well as stripline transitions have been developed.
\end{abstract}

\section{Introduction}

Microstrip Patch antennas are widely used in modern communication, radar and aerospace systems [1], [2]. In some systems, like synthetic aperture radar (SAR) dual frequency operation and dual-linear polarization, with low cross-polarization capability are desired. Also additional requirements for low side-lobes, $\operatorname{cosec}^{2}$ radiation pattern and wide-band operation result in complex design of an antenna beam forming network (BFN) design. The feeding network has to incorporate matching circuits enabling matched wide band operation of antenna elements together with different types of power dividers/combiners providing proper, usually nonuniform, power distribution to antenna elements. To provide dual-linear polarization capability with low crosspolarization coefficient good isolation between the individual parts of the BFN must be assured. All these requirements suggest an application of multilayer structure where different parts of BFN are placed on different layers and good isolation can be easily achieved, when stripline technology is applied. Multilayer structure requires a number of interconnections between layers (vias). The possibility of excitation of leaky modes that can significantly deteriorate properties of BFN must be taken into account. In this paper we present the design of such a multilayer BFN for a C-band dual-linear polarized antenna for radar application.

\section{The BFN arrangement}

The antenna discussed in this paper operates in C-band and is part of the dual-frequency dual-linear polarization antenna array presented earlier in [3]. The antenna consists of $3 \times 64$ radiating elements arranged in $8 \times 8$ element array. Each element is fed by two probes one for horizontal and one for vertical polarization. The feeding probe positions are rotated to provide low cross-polarization and low sidelobes by the method invented in DTU [4] and are presented in Fig. 1.

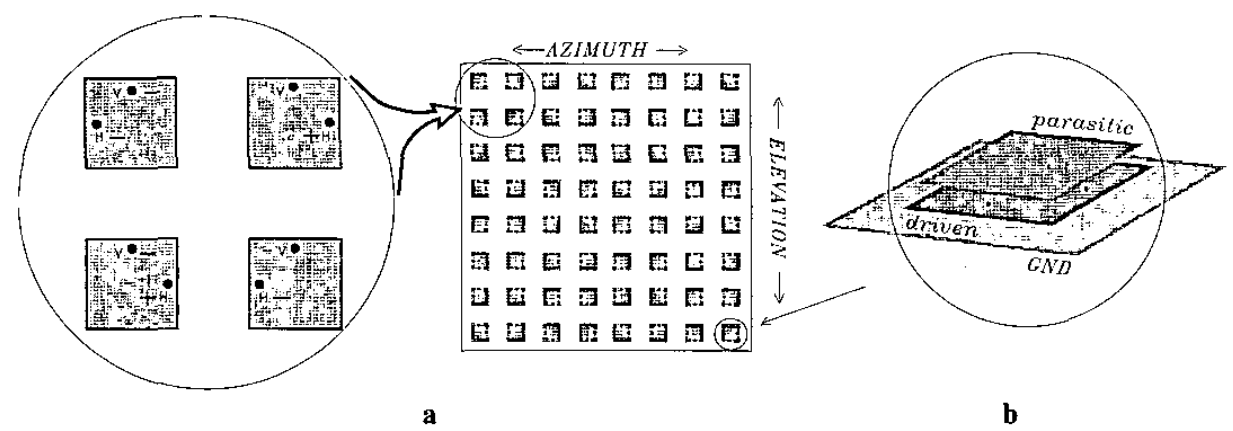

Fig. 1 The $8 \times 8$ elements antenna array a) positions of feeding probes for vertical and horizontal polarization b) single stacked microstrip patch antenna element

$A \operatorname{cosec}^{2}$ pattern is demanded in elevation plane. As a result the power distribution is non-uniform and the signal delivered to each column of antenna array must have different amplitude and phase. In Fig. 2 the arrangement for the feeding network in elevation plane is presented together with the desired excitation coefficients. The scheme of this part of BFN is identical for both horizontal and vertical polarization. In azimuth plane the uniform power distribution have been chosen, however because of the special positioning of feeding probes $180 \mathrm{deg}$ phase shift must be provided in the power divider network. As a result in azimuth plane the feeding networks for horizontal and for vertical polarizations have different layouts. This is presented in Fig. 3.

\footnotetext{
G. Jaworski and V. Krozer (Electromagnetic Systems Section, EMI, Ørsted•DTU, Danish Center for Remote Sensing, Technical University of Denmark, Kgs. Lyngby, Denmark) E-mail: g.jaworski@plusnet.pl, vk@oersted.dtu.dk
} 


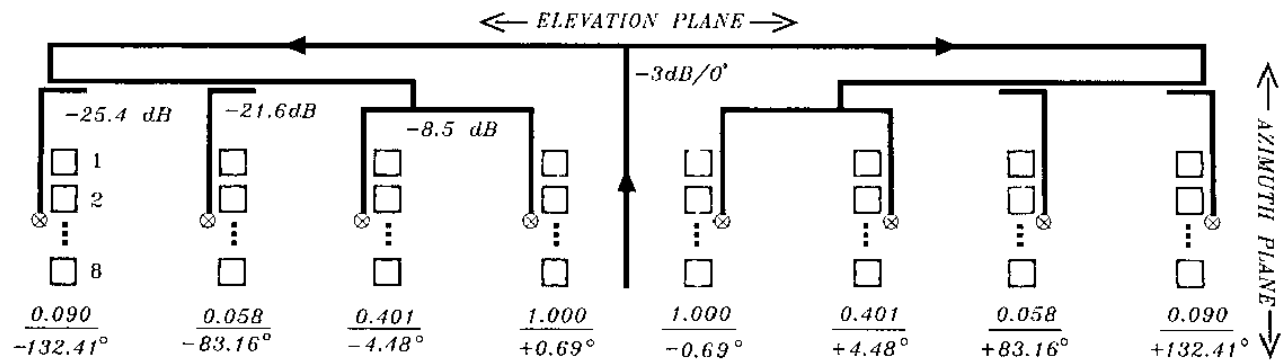

Fig. 2 The BFN arrangement in elevation plane

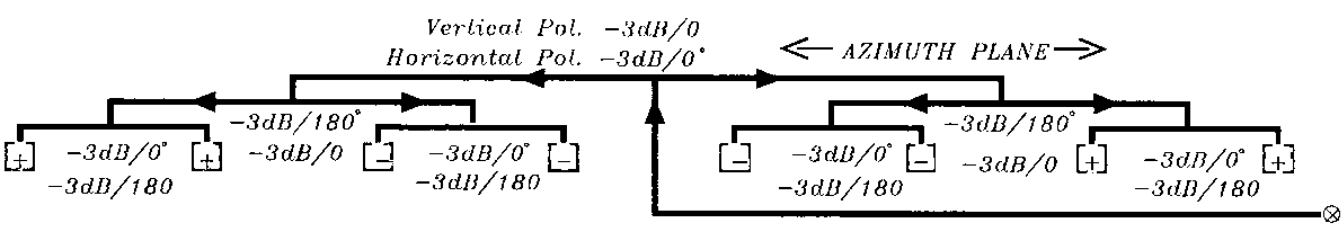

Fig. 3 The BFN arrangement in azimuth plane for vertical (red) and horizontal (blue) polarization

Matching circuits.

In the dual-frequency stacked microstrip patch antenna configuration a matched bandwidth of less than $5 \%$ is achievable due to the restrictions in the substrate thickness of the layers and the necessity of sharing substrates [3]. High-resolution SAR systems demand antenna arrays with wideband (around $8 \%$ or larger relative bandwidth) and low return loss $(\leq-15 \mathrm{~dB})$ capabilities, exceeding the operational bandwidth of microstrip antennas without impedance matching structures. To meet these requirements a novel approach for the matching of individual antenna elements of an antenna array has been applied [5]. The layout of the matching circuit and the measured results are presented in Fig. 4.

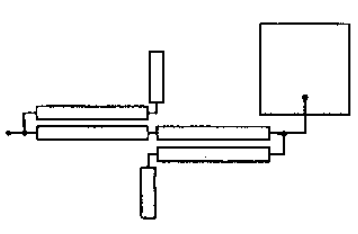

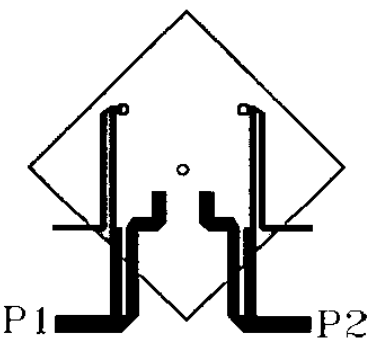

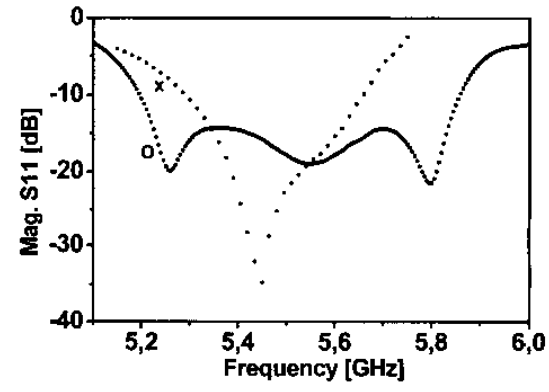

c

Fig. 4 Matching circuits for single antenna element a) matching circuit arrangement with two coupled lines sections $b$ ) manufactured layout of the antenna patch together with matching circuits

c) measured return loss versus frequency before ( $\mathbf{x}$ ) and after (o) matching

\section{Power dividers/combiners.}

In elevation plane highly non-uniform power distribution is required for the realization of $\operatorname{cosec}^{2}$ radiation pattern. Consequently, the power division network consists of different types of power splitters providing various power division ratios. For moderate power division ratio $(-8.6 \mathrm{~dB})$ the Gysel-type power dividers have been applied to overcome the problem with very high and very low transmission line characteristic impedances that appears in Wilkinson's power dividers [6]. For high power splitting two directional couplers providing $-21,6$ $\mathrm{dB}$ and $-25,4 \mathrm{~dB}$ coupling have been applied. In Fig. 5 the layout of 1 to 8 power divider is presented. To realize the uniform power distribution in azimuth plane the standard Wilkinson's type and hybrid ring power divider have been designed. The hybrid ring provide the desired $180 \mathrm{deg}$ phase shift between adjacent antenna elements. The layouts of power dividers for horizontal and vertical polarization are presented in Fig. 7 and measured performance in Fig. 8. 


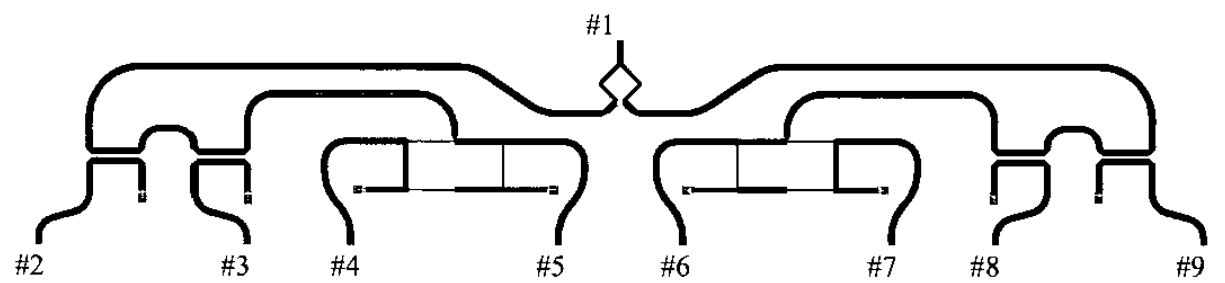

Fig. 5 Layout of the power divider network with non-uniform power distribution.

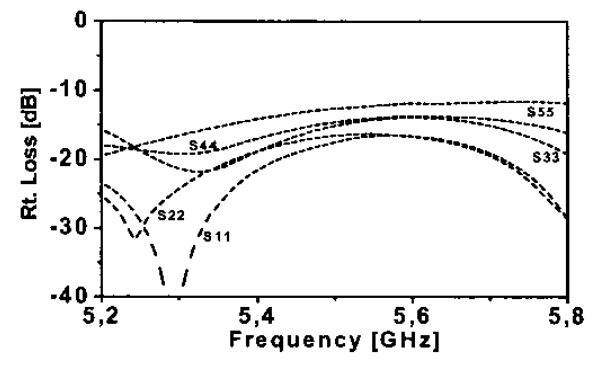

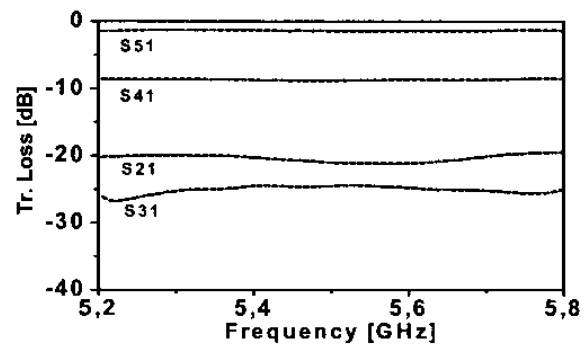

b

Fig. 6 Measured a) Return Loss and b) Transmission Loss characteristics of the left part of the power divider network with non-uniform power distribution
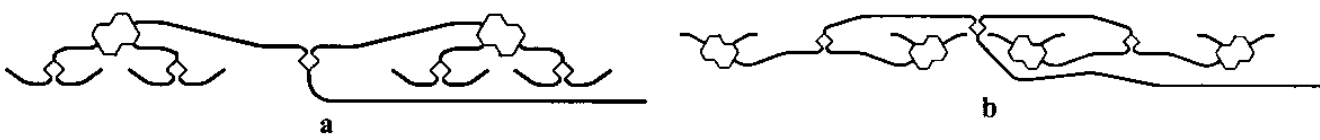

Fig.7 The layouts of power dividers providing uniform signal distribution in azimuth plane for a) horizontal and b)vertical polarization

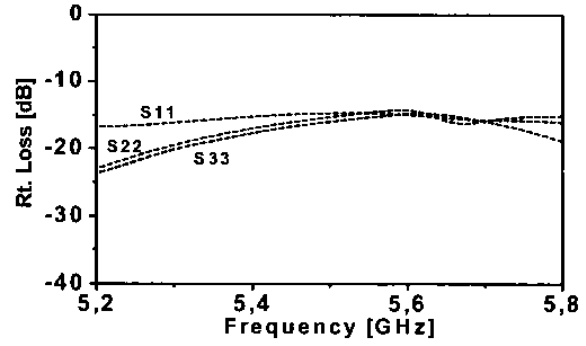

a

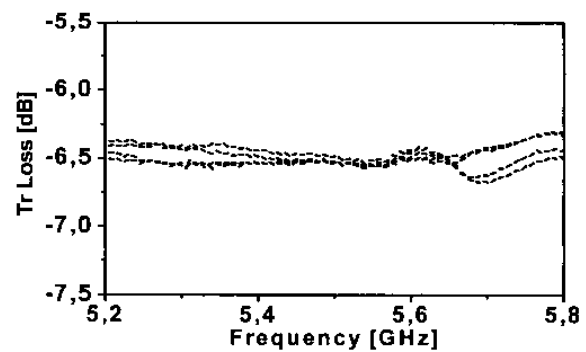

b

Fig. 8 Measured a) Return Loss and b) Transmission Loss characteristics of left part of the power divider network with uniform power distribution (Fig. 7 b)

\section{Connections between layers}

Numerous vias have to be employed in order to assure necessary connections between BFN parts placed on different layers. Some of these are buried inside the structure and not accessible after manufacturing. By proper design of manufacturing sequence it is possible to provide necessary access during the manufacturing process. Presence of via discontinuity in multilayered environment creates the possibility of launching leaky modes [7]. As a result significant crosstalk to other lines and deterioration of via transmission loss appears. This phenomenon is not clearly visible from return loss characteristics. Several techniques for suppression of those parasitic modes have been reported [7], [8]. In the present BFN design, novel type of strip-vias with additional 
grounding strips illustrated in Fig. 9 a have been applied. This technique successfully inhibits the excitation of leaky modes which leads to a significant reduction of via transmission loss.
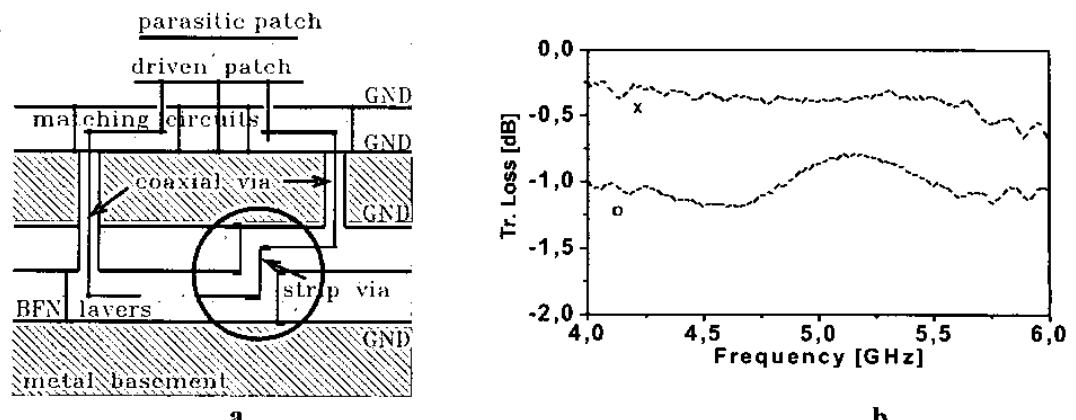

b

Fig. 9 The cross-section of multilayer antenna structure. In the circle cross section of strip via with two additional strips connected to ground planes is presented b) comparison of measured transmission loss

for strip via with (x) and without (o) additional grounding strips

\section{Conclusion}

The paper presents a successful broadband design of a beamforming network for $8 \times 8$ antenna array at Cband. The BFN employs novel approaches in antenna matching and stripline via structure. The BFN is realised in multilayer strip-line technology on Rogers RT 5870 substrate. The overall BFN parameters are summarized in Table 1 .

\begin{tabular}{|l|lc|}
\hline Bandwidth (VSWR $\leq 1.5)$ & fc $\pm 200[\mathrm{MHz}]$ & S/M \\
\hline Overall loss of BFN from input to antenna element & $2.5[\mathrm{~dB}]$ & $\mathrm{S} / \mathrm{M}$ \\
\hline Return Loss at input & VSWR $\leq 1.5$ in $(5.2 \div 5.8)[\mathrm{GHz}]$ & $\mathrm{M}$ \\
\hline Return loss at antenna clement & VSWR $\leq 1.5$ in $(5.21 \div 5.85)[\mathrm{GHz}]$ & $\mathrm{M}$ \\
\hline Overall radiation efficiency & $47 \%$ & $\mathrm{~S}$ \\
\hline
\end{tabular}

Table 1. BFN parametrers. S-simulated (Agilent ADS or Momentum), M- measured

\section{References:}

1. GHORBANI, K. and WATERHOUSE, R. B.: 'Design of large broadband patch arrays', IEEE International Symposium Antennas and Propagation Society 1999, vol. 2, pp. 928-931, 1999.

2. JAMES, P. and POTTER, S.V.: 'A wideband microstrip patch array for a MicroSAR', Twelfth Intern. Conf. on Antennas and Propagation. ICAP 2003, pp. 707-711, 200

3. GRANHOLM, J.: 'Dual-Frequency and Dual-Polarization Antennas', Ph.D.Thesis, Department of Electromagnetic Systems, Technical University of Denmark, August 2000.

4. GRANHOLM, J. and WOELDERS, K.: 'Dual polarization stacked microstrip patch antenna array with very low cross-polarization', IEEE Trans. On Antennas and Propagation, vol. 49, no. 10, pp. 1393 $1402,2001$.

5. JAWORSKI G. ,KROZER V., Broadband Matching of Dual-Linear Polarization Stacked Probe-Fed Microstrip Patch Antenna, Submitted to Electronic Letters.

6. SAWICKI, A., SACHSE, K., JAWORSKI, G., KABACIK, P. Comparison of planar antenna feed networks with Wilkinson and coupled-line power dividers, XII Int. Conf. on Microwaves \& Radar MIKON-98, Poland, Kraków, May 20-22, 1998, vol. 2, pp. 423-427.

7. ABHARI, R., ELEFTHERIADES, G.V. and VAN DEVENTER, E.,: 'Equivalent circuit for multiple vias in parallel plate environment', Electronic Letters, vol. 36, No.17, 2000.

8. PILLAI, E. R.: 'Coax Via - A technique to Reduce Crosstalk and Enhance Impedance Match at Vias in High-Frequency Multilayer Packages Verified by FDTD and MoM Modeling', IEEE Transactions on Microwave Theory Tech., vol. 45, Oct. 1997, pp. 1981-1985.

9. NGHIEM, D., WILLIAMS, J.T., JAKSON, D.R. and OLINER A.: 'Suppression of Leakage on Stripline and Microstrip Structures', IEEE MTT-S Digest, 1994. 